-(ARTAUD, Antonin. OEuvres complètes. t. II. Paris: Gallimard, 1980: 223- 227.)

"Dire que j'aime complètement ces eaux-fortes de Jean de Bosschère, je ne le dirai pas; elles ne sont pas assez obscures. [...] Le peintre n'a pas voulu ou n'a pas su garder son secret. (Ibidem: 225.)

(Ibidem: 227.)

\section{LIMITES DA ESCRITA OU COMO FAZER DA ESCRITA UMA PLÁSTICA POÉTICA?}

Ana Kiffer

O presente artigo pretende revisitar o último período de criação do escritor francês Antonin Artaud (1896-1948), que se concentra, sobretudo, nos seus últimos três anos de vida (1945-1948), sem deixar de dialogar com toda a sua obra, para interrogar o procedimento artístico que fez com que, naquele momento, Artaud escrevesse e desenhasse ao mesmo tempo. Tal procedimento será pensado como indício de um inconformismo nevrálgico, muito anterior em sua obra, que subsistia numa relação sempre falha com a escrita. Um escritor que só se autorizava a escrever a partir do contato e da potência de uma escrita falhada e ausente, em sempiterno estado de privação. Limites da escrita que o procedimento plástico-poético ulterior vem reatualizar, agora num desejo expresso de alargamento, de explosão, de expansão de todo quadro, de todo enquadramento, linha ou suporte.

Em 1929 Artaud escreve o prefácio ao livro de águas fortes de Jean de Bosschère* num tempo ainda distante deste em que veremos surgir sua "nota febril", ${ }^{1}$ mas em que já se delineiam as bases fulminantes das suas idéias, que posteriormente se farão "novos corpos de sensibilidade". ${ }^{2}$ Seu prefácio é duro e mesmo cruel: "Dizer que amo completamente essas águas-fortes de Jean de Bosschère, eu não o direi: elas não são suficientemente obscuras. [...] O pintor não quis ou não soube guardar seu segredo".* Talvez por essa razão o texto tenha sido destinado a tantos anos de silêncio. Somente em 1978 ele seria recuperado e desenterrado dos arquivos de Bosschère em Bruxelas. Mas seu silêncio não pertence de todo ao pintor, posto que no pretendido prefácio Artaud trespassaria as telas de Bosschère para incisivamente perfurar os "maneirismos" ou "fetichismos" em pintura." Artaud busca num primei-

\footnotetext{
${ }^{1}$ Referência extraída de texto inédito, escrito em 1947 e intitulado 50 dessins pour assassiner la magie.

${ }^{2}$ Ver nota acima.

3 "Mais ces gens qui ne sont pas parvenus à se débarrasser du fétichisme de la valeur, ces gens qui partis d'une caricature d'angoisse et d'authentique bouleversement s'obstinent à se conformer à la hiérarchie des attaches humaines, Jean de
} 
ro momento criticar esse artificialismo - aliado ao didatismo - para posteriormente dele se separar através de suas criações poéticoplásticas. Sua crítica a Bosschère recai sobre aquilo que identifica como sendo a busca desesperada e "mental" ${ }^{*}$ de criar um estado seja de "azedume ou de angústia". Ao estado criado, querido, mental, Artaud contrapõe a imagem de "uma chama verde que treme à ponta rasgada de um grito". Imagem que se oferece poeticamente como gesto dilacerador das forças. Imagem centrada na idéia de movimento, mais do que de movimento, de abalo - tremblement em francês, do latim tremulare -, imagem própria à chama. $\mathrm{O}$ que parece importar ao poeta - aquilo que se torna o alvo de sua crítica já aqui em 1929 - é que a imagem é força ou não é. E que toda possibilidade de representação da força deriva de uma possibilidade de flagrar o tremular de um corpo, resultado inicial do contato de um corpo com outro corpo, como, por exemplo, do fogo com o ar. A força é o resultado desse encontro. Nessa direção ele viria escrever em 1946 que é preciso "desimaginar as imagens". 5* Quer dizer: ao invés de uma imagem arrumada mentalmente, soldada pela imaginação, o escritor deseja o campo real do encontro entre os corpos, o campo possível de manifestação das forças em contraposição à idéia. Só assim ele poderá contrapor ao estado mental (enquanto vontade, imaginação, razão, cérebro) um outro estado, em que agem as forças.

Na primeira frase do texto sobre as águas-fortes, ele define: "A uma doença do pensamento corresponde a aparição de uma certa pintura." ${ }^{*}$ Daí, resta ao poeta separar a autenticidade ou não das aparições que se rendem a uma "doença do pensamento". Sabemos que, se Artaud fala ou escreve sobre qualquer outra figura artística, ele o faz do ponto de vista daquele que sofre e aí "tem o direito à palavra", do ponto de vista daquele que vive a doença do pensamento para além de um contra destinado a recriar outras verdades

Bosschère avec ses faiblesses, ses manies littéraires, ses préjugés moraux même a beaucoup plus qu'eux le sens de la véritable liberté."

4 "L'amertume désespérée des eaux-fortes de Jean de Bosschère est mentale, donc voulue, elle n'est pas la flamme verte qui tremble à la pointe déchirée d'un cri.”

5 "Le problème est de se situer dans l'au-delà de l'être et de sa notion réflectrice de conscience. [...] cogner, souffrir, se déchirer, se barder, ne pas penser... désimaginer les images [...]." Grifo nosso. Frisamos que no corpo do poema Artaud alude à necessidade de sair da consciência reflexiva em proveito de uma consciência propulsiva. Da mesma maneira que se deveria sair da imagem-imaginação em proveito de uma imagem-força.
(Ibidem: 226.)

" (ARTAUD, Antonin. CEuvres complètes. t. XXII. Paris: Gallimard, 1986: 19.)

* (ARTAud, Antonin. OEuvres complètes. t. II. Op. cit.: 223.) 
" "Il y a l'hermetisme où l'on n'entre pas parce qu'il est fermé,/ celui où l'on entre et qui vous enferme,/ celui qui vous invite à entrer pour ouvrir ce qui est fermé". (ARTAUD, Antonin. OEuvres complètes, t. XIV. Paris: Gallimard, 1978: 123.)

- Parmi ces eaux-fortes, les plus étranges, les plus significatives aussi, sont de beaucoup les plus ratées. Par la disharmonie profonde qu'elles établissent entre ce que les crétins appellent la pensée et la forme, et moi: l'idée et le trait. e certezas. ${ }^{6}$ Sublinha-se, por conseguinte, que os limites, as falhas, as perdas, o "impoder" da linguagem e do pensamento tornam-se as matérias que lhe permitem falar, escrever, criar. Além disso, elas seriam as passagens entre o poeta e Abelardo, Heliogábalo, Lewis Carroll, Van Gogh, Lautréamont, e outros. Essa passagem que contamina e deixa contaminar o poeta e as "personagens" que ele revisita e recria em seus textos. Rejeitando o caráter de infecção - enquanto força que esburaca os corpos e neles cria passagens, aberturas -, imobilizaríamos sua poética do pensamento criada na tensão perfurante (na abertura, na passagem) entre texto e leitor/destinatário, entre a perda da linguagem e sua aparição, entre a produção do pensamento e sua constante perda conceitual, entre a doença e sua cura. É assim que encontramos o hermetismo ${ }^{7}$ de Artaud, ou como ele mesmo escreveu nas Interjeiçôes: "Há o hermetismo em que não se entra porque é fechado,/ aquele em que se entra e que nos enclausura,/ aquele que nos convida a entrar para abrir o que está fechado". Assim também se perfaz seu prefácio a Jean de Bosschère: crítica tomada do ponto de vista de sua própria crise, cuja matéria (que agora nos interessa) é o que vai anunciar seu próprio devir criativo através de uma preocupação central que, nesse momento, assim se enuncia:

Entre as suas águas-fortes, as mais estranhas, e as mais significativas também, são de longe aquelas que mais fracassaram. Pela desarmonia profunda que elas estabelecem entre o que os cretinos chamam de pensamento e forma e eu chamo de idéia e traço.

Numa primeira instância dever-se-ia lembrar que toda crítica contundente de Artaud gesta uma ampla recusa aos pertencimentos escolares. Tal recusa já foi lida (principalmente no fim dos anos 1960 e 1970) como sendo interdição de se pensar (com) Artaud. Interdição que vetou à sua obra uma própria produção de pensa-

\footnotetext{
${ }^{6}$ Sublinhamos que apesar das consonâncias e afinidades entre Artaud e as vertentes de vanguarda - sobretudo a surrealista - nosso poeta vai retirar da força de negação uma matéria vital cujo destino não se estabelece na imediata formação de uma escola ou doutrina mas, ao contrário, da instabilidade inserida doravante nesses domínios se requer um movimento constante de interrogação, uma impossibilidade de se ver "formado" que destina ao pensamento (e à linguagem) sua constante perda de si mesmo. A negação assume, além de sua força afirmativa, uma força de invenção.

${ }^{7}$ Traço tantas vezes convocado por seus leitores face aos seus últimos textos, oferecendo-lhes até mesmo o caráter de ilegibilidade, como bem observou Evelyne Grossman em Artaud Joyce, le corps et le texte.
} 
mento. Interdição calcada na exigência de que só podemos "experimentar" Artaud. Tratava-se, sobretudo, de um Artaud homem de teatro - fazendo, muitas vezes, com que a recepção de sua obra se limitasse aos primeiros textos do poeta, até a década de 1930. Um dos destinos possíveis dessa recusa - que se sobrepôs à recusa do poeta - é aquele que oferece à obra um caráter de desconhecimento e/ou de esquecimento no interior dos movimentos modernos das artes plásticas e da literatura. Todavia não podemos esquecer que tais recusas se firmavam na reivindicação de uma determinada época, em que os "preceitos" de liberdade e experimentação cumpriram seu papel fundamental de alteração da ordem estabelecida. E ainda soma-se o fato de que nessa mesma época a obra de Artaud mal começava a ganhar um sopro de publicação. Além disso, sua recepção não deixaria de impor dificuldade: dada sua multiplicidade de domínios, sua extensão correlata à intensidade, seu vasto espectro de transformações e contradições inerentes, sua força combativa constante que resistiria implacavelmente às tentativas de inserções unívocas em escolas literárias ou plásticas.

A partir dessas observações, duas direções merecem ser destacadas na crítica contundente do poeta. Uma que se relaciona com o contexto artístico em que se insere o prefácio escrito em 1929. Outra que incide sobre sua própria obra, tomada a partir de sua publicação em 1946. No entanto, haveria ainda o encontro dessas duas direções. Assim destacamos desde já a presença de uma linha de força que se mantém em toda a trajetória do poeta. Trata-se da pregnância ("as telas mais significativas") da idéia de tudo aquilo que é falhado, rateado ("as mais rateadas"). É assim que, ao lado de sua crítica a Jean de Bosschère, vemos reverberar o lugar ao qual ele viria destinar toda a sua obra, quando da escrita de seu próprio prefácio em 1946 - "Sei que quando quis escrever minhas palavras ratearam, e pronto". Nesse ponto não leríamos a crítica a Bosschère como recusa (de suas águas-fortes), mas, sim, como afirmação do universo pictural e poético possível em Artaud. Aqui já deveríamos introduzir a pergunta inicial: o que portam os traços para Artaud? Sua significância residiria no fato de que eles poderiam suportar a presença da força? E da força em sua constância dilacerante ou em sua intermitência abrupta, o tremular assim como o incisar? O traço implica a imediata ação de traçar e, como toda ação, arrasta em si a força. Naquilo que seria próprio à matéria plástica, poder-se-ia dizer que o ratear é justamente o que o traço
" "Je sais que quand j'ai voulu écrire j'ai raté mes mots et c'est tout." (ARTAUD, Antonin. OEuvres complètes. t. I. Paris: Gallimard, 1994: 9.) 
"cette sorte de vie glaireuse qui se traîne entre les lignes ou dans le corps des lignes mêmes" (ARTAUD, Antonin. CEuvres complètes, II. Op. cit.: 226.)

- "Je n'ai pas de moi, mais il n'y a que moi et personne,/ pas de rencontre possible avec l'autre,/ ce que je suis est sans différenciation ni opposition possible./C'est l'intrusion absolue de mon corps, partout." (ARTAUD, Antonin. OEuvres complètes. t. XIV. Op. cit.: 76 , grifo do autor.).

(RIOUT, Denis. Qu'est-ce que l'art moderne. Paris: Folio Gallimard, 2000: 53.) pode portar e suportar. Ele o traz em si: lascas, rachaduras, fendas, sulcos, nesgas, rugas, pregas, cortes. Essa "vida pegajosa que se arrasta entre as linhas ou no corpo mesmo das linhas", " como disse o poeta ainda nesse texto de águas-fortes. Conhecendo os desenhos de Artaud, pode-se ler, já aqui, o anúncio de suas aparições plásticas, que não entregariam senão a própria encenação mesma dessa vida pegajosa, percorrida tão só e simplesmente através de seus próprios traços. Só a partir dessa constatação - que atravessa a obra de Artaud - é que poderemos nos voltar em direção aos "cretinos do pensamento e da forma” para, em seguida, buscarmos operar e desenvolver aquilo que o autor reivindica como sendo "idéia e traço" nos seus próprios desenhos-escritos.

Seria, portanto, ao vislumbrar esse vasto espaço de ebulição, que proporíamos introduzir a questão plástica e pictural em Artaud: trabalhando na tensão que recusa o domínio da arte mas que, através dessa própria recusa, nele promove sua inserção. É assim que suas críticas contundentes serão apresentadas aqui como expressão de sua própria singularidade. Mais ainda: como manifestação da problemática ou da questão própria à sua obra: "Não possuo um eu,/ mas só há a mim e ninguém mais,/ nenhum encontro possível com o outro,/ o que sou é sem diferenciação nem oposição possível./ É a intrusão absoluta de meu corpo, em todos os lugares". * É assim, também, que suas possíveis consonâncias não deverão ser lidas como "rótulos" escolares, mas como campos de convergência de forças, que retiram a obra do poeta do silêncio asilar, ou dos equívocos de unicidade, orquestrando-a nas vozes contundentes e nas controvérsias do século XX.

Desse modo, em sua crítica ao pensamento e à forma, não se poderia negligenciar o espaço de ebulição e de controvérsias potencializado com as vanguardas artísticas desde o primeiro decênio do século XX. Apesar de conhecermos as inúmeras portas de passagem e transformação no domínio das artes desde fins do século XIX, as vanguardas do século XX "passaram ao ato" e foram recebidas como uma verdadeira revolução. É assim que - em sua crítica aos "cretinos" feita em 1929 - não deixamos de ouvir algumas das exigências formais impostas sobretudo pela vanguarda abstracionista. Em 1913, Fernand Léger já apontava "as três grandes quantidades plásticas: as Linhas, as Formas e as Cores"* que, nos anos 1920, tornar-se-iam os elementos plásticos por excelência. Nesse sentido, poder-se-ia identificar, na crítica do poeta ao pensamento 
e à forma, certo manifesto contra aquilo que, no abstracionismo, corria o risco do puro ornamento, de um espiritualismo desatado por completo do corpo e/ou da matéria, contra uma arte que deveria ser recebida, codificada e processada pelo cérebro. Tal crítica, como vimos no prefácio a Bosschère, é ampliada do "cérebro" enquanto locus da razão para o "cérebro" enquanto locus "mental" englobando, por conseguinte, a razão e a emoção. O dever e a vontade. $\mathrm{O}$ julgamento e o sentimento. E é assim que a posição crítica do poeta se complexifica, vazando a vanguarda abstracionista e as águas-fortes de Bosschère para se inserir num campo de recusa mais amplo. Campo este que poderia ser localizado - no interior das reivindicações de uma arte moderna - nas plásticas comprometidas com o formal, mas também naquelas que se relacionariam com um fundo psicológico - poço de emoções e sentimentos - a ser expresso, liberado ou representado.

É nessa tensão - que recusa a razão e também a emoção que podemos discutir sobre as convergências e divergências entre o poeta e algumas das vertentes reivindicativas postas pela revolução moderna na arte. Como alertamos, suas relações de divergência estariam calcadas na recusa de qualquer estado de "supervisão" - seja este da razão ou do sentimento e da emoção. Ou seja: operamos aqui com uma recusa de toda e qualquer mediação, como ele escreve em suas Interjeições:

Quando minha mão queima, ela queima. Há o fato que minha mão queima, o qual, se penso sobre ele, fica ameaçado enquanto fato,/ ter o sentimento de que minha mão queima é já entrar noutra esfera, se tenho a idéia que minha mão queima, já não estou na minha mão mas sim num estado de supervisão.

É assim que Artaud se distanciaria das mediações da razão (e do cérebro) promovidas - na modernidade - sobretudo pela da arte abstrata, e também das mediaçôes subjetivas propostas principalmente através da vanguarda surrealista. No entanto, e antes de desdobrarmos a reivindicação singular do poeta em torno ao "fato", não podemos deixar de atentar para como se insere seu gesto plástico no contexto das vanguardas acima citadas.

O primeiro ponto a destacar é o fato de que sua plástica-poética se apresenta a nós numa perspectiva que rasga a pregnância do narrativo e/ou do figurativo, o que aliás também é o desejo da arte abstrata. Como escreveu a partir de seus desenhos: "não há um único que não responda a uma atividade fisiológica real/ que não
'Quand ma main brûle, elle brûle./Il y a le fait que ma main brûle, lequel déjà, si j’y pense, est, comme fait, très menacé,/ avoir le sentiment que ma main brûle, c'est rentrer dans un autre rayon,/ si j'ai l'idée que ma main brûle, je ne suis déjà plus dans ma main mais en état de supervision. (ARTAUD, Antonin. CEuvres complètes, t. XIV. Op. cit.: 80.) 
. "... pas un qui ne réponde à une activité physiologique réelle,/ qui n'en soit,/ non pas la traduction figurative/ mais quelque chose comme le crible efficace,/ sur le papier matérialisé." (ARTAUD, Antonin. CEuvres sur papier. Marselha: Réunion des musées nationaux, 1995: 60, grifo do autor.)

(Kandinsky, Wassily. Du spirituel dans l'art, et dans la peinture en particulier. Paris: Folio, 1999.)
- Certes, les moyens idéels ne sont pas dépourvus de matière, sinon on ne pourrait pas écrire. Quand j'écris le mot vin avec l'encre, celle-ci ne tient pas le rôle principal mais permet la fixation durable de l'idée de vin. L'encre contribue ainsi à nous assurer du vin en permanence. Écrire et dessiner sont identiques en leur fond. (KLEE, Théorie de l'Art Moderne. Paris: Folio, 1999: 58, grifo do autor.) seja,/ não a tradução figurativa,/ mas algo como o crivo eficaz,/ materializado sobre o papel". 'Mas destaca-se para o poeta o fato de que tal rompimento com o figurativo não viria a se processar enquanto abandono do corpo em proveito do intelecto, da razão ou "do lado espiritual na pintura e nas artes"* - em resumo: o rompimento com o figurativo não se rende à forma abstrata. $\mathrm{O}$ ponto crucial que separa Artaud dos preceitos de uma arte do pensamento e da forma seria justamente sua insistência sobre a corporalidade, sobre a materialidade - "resposta a uma atividade fisiológica real".

Mas a discussão ainda deveria se aprofundar, posto que o não figurativo em Artaud encontra ressonância na busca de crivar os corpos com as forças que os atravessam, fazendo com que em sua plástica nos encontremos sem a possibilidade de figurar/ narrar corpos mas permanecendo, ainda assim, diante deles. E é aqui que encontramos outro índice que o conjuga - e num ponto mais preciso e mais profundo do que o anterior - com parte do pensamento abstrato: ${ }^{8}$ esses corpos não figurativos da plástica artaudiana são corpos-força, o crivo é eficácia em fisgar, atravessar, perfurar com as forças os corpos. Seria possível dizer que as forças seriam a base de toda e qualquer matéria. E mesmo quando se trata de abstração ou construção de meios ideais. É assim que Paul Klee pôde afirmar que:

Decerto os meios ideais não são desprovidos de matéria, senão não se poderia escrever. Quando escrevo a palavra vinho com tinta, essa última não tem o papel principal mas é quem permite a fixação durável da idéia de vinho. A tinta contribui, desse modo, em nos garantir vinho em permanência. Escrever e desenhar são no fundo idênticos.

Para Artaud, seria justamente a partir desse "fundo de identidade" que ele poderia inaugurar sua plástica-poética ou seus desenhos-escritos. E a pregnância da matéria, assim como seu caráter de fixação e duração, viria instalar-se enquanto vetor de força que atravessa os corpos. Eles serviriam menos à idéia e mais à própria possibilidade de materializar as forças que perpassam corpos (sempre escritos ou desenhados). Dito de outra maneira: a fixação se manifestaria como força de impressão (tomada aqui enquanto

\footnotetext{
${ }^{8}$ Dever-se-ia ressaltar que tanto Paul Klee quanto W. Kandinsky se preocuparam em não fazer da abstração uma arte de recusa do material e total pregnância do puro "formal". Ainda, no projeto pictural de Klee as forças se tornariam a valência visível por excelência.
} 
"contato de um corpo com o outro") e a duração, como manifestação de presença da força.

Nesse sentido, interessa destacar a partir do "Prefácio" escrito em 1929 a aparição de certa idéia acerca do traço que se manifesta enquanto combate contra a linha. A linha a ser combatida (dentro desse contexto histórico) é a linha abstrata desencarnada e, mais além, a linha que compõe a linearidade do discurso, seu logocentrismo. A linha que define, por excelência, o horizonte e o limite de toda e qualquer escrita ocidental. No entanto, como estamos buscando inserir a voz do poeta no interior das turbulências provocadas nas vanguardas, dever-se-ia notar o caráter de possibilidade que se abre também a partir desse mesmo contexto - de um perfazer plástico que não se renda aos domínios do mental e que se desembarace das imposições do mundo das representações. É assim que seus desenhos visam a perfazer explosões de corpos ou, como ele disse, visam à construção de "corpos animados". ${ }^{9}$ Diríamos que a aliança que anima os corpos é a aliança com as forças. Se, para os abstratos, as forças serviriam à fixação da forma (da idéia), para Artaud, elas se abrem como potências demolidoras do dado fixo. Assim, não capturadas pela forma, as forças se manifestariam em seu gesto pictural através do crivo. Tal gesto se vai relacionar com a precisão, e, portanto, com a crueldade, posto que não se trata tanto da precisão da linha nem da forma, relacionando-se mais com a precisão de um gesto que perfura até mesmo o suporte, como se observa em toda a sua produção dos Sorts. Nesse texto e contexto das Águas Fortes poder-se-ia dizer que a força se manifesta destituindo a preocupação mental - "artificial" - para ir de encontro à "idéia que se insinua pegajosa no corpo das linhas".

Em 1947, por ocasião de uma exposição dos seus desenhos e retratos na Galérie Pierre Loeb em Paris, Artaud escreve um texto plaqueta que assim termina: "É assim que é preciso aceitar esses desenhos na barbárie e na desordem de seu grafismo, que jamais se preocupou com a arte mas sim com a sinceridade e espontaneidade do traço." ${ }^{* *}$ Como falar de espontaneidade e sinceridade sem ser capturado pelas representações do mental? Em primeiro lugar, valeria frisar que a espontaneidade para o poeta refere-se exclusivamente ao traço: "espontaneidade do traço"! Mas, então, como adentrar

9 "Parce que je n'ai cessé à Rodez de fabriquer des corps animés." (ARTAUD, A. "Lettre Inédite à Pablo Picasso - 3 janvier 1947". In: Revue Europe. Numéro Artaud, n. 873-874, jan-fév. 2002.
" "C'est ainsi qu'il faut accepter ces dessins dans la barbarie et le désordre de leur graphisme qui ne s'est jamais préoccupé de l'art mais de la sincérité et de la spontanéité du trait." (ARTAUD, Antonin. OEuvres sur papier. Op. cit.: 207.) 
(DALí, Salvador. "Cómo devenir paranóico-crítico ". In: Confessiones Inconfessables. Barcelona: Bruguera, 1975.) nesse domínio do traço? O traço pode ser espontâneo? Começaremos por excluir aqueles domínios do mental. É precisamente aqui que Artaud se diferencia de uma plástica e de uma poética surrealistas. Lembramos que em 1929 - por ocasião da escrita do Prefácio" a Bosschère - Artaud já havia se desligado do grupo surrealista. Além disso, no seu retorno à cena artística parisiense - a partir de 1946 -, ele não deixaria de rever e repensar traços importantes que o separavam dos surrealistas já na década de vinte.

Nesse sentido, começaríamos por indagar: como se diferencia a espontaneidade para Artaud do automatismo surrealista? $\mathrm{Nu}-$ ma primeira instância, insistimos: a espontaneidade não se rende ao sujeito, não se enuncia aqui nada que se assemelhe a um reduto automático de um inconsciente subjetivo. A espontaneidade pertence ao próprio traço, por mais bizarro que isso nos pareça. Só assim é que a idéia de traço em Artaud (quando da aparição de seus desenhos) não vai contemplar a busca de novos meios (técnicos ou expressivos), nem qualquer "preocupação com a arte". São movimentos conjuntos: a recusa de um núcleo sujeito e a recusa dos meios artísticos. É precisamente através dessa recusa que o poeta precisa sua espontaneidade: desligando-se de uma intervenção que busca "conquistar com a razão o irracional"* e vice-versa, como seria a aliança entre a crítica e a paranóia para Salvador Dali. Mas é também desligando-se de um tratamento posterior ao gesto pictural, o que inseriria a invenção e o acaso (muitas vezes inerente ao processo criador) num regime de determinaçôes discursivas, sejam estas de um discurso sobre a arte ou sobre o sujeito. Ora, a conjunção dessas duas recusas é exatamente aquela que viria a ser explorada na plástica surrealista: a busca de novos meios (técnicos ou expressivos) para obter os benefícios fornecidos pela escrita automática e a sistematização discursiva dos surrealistas pautada numa interpretação do inconsciente freudiano. Nesse domínio destacaríamos as intervençôes plásticas e discursivas de Salvador Dalí que, munido de seu método paranóico-crítico, recorre às técnicas ilusionistas para traduzir imagens oníricas ou, ainda, as pinturascolagens como meio direto de tradução do automático.

Mas as diferenciaçôes entre a plástica-poética de Artaud e a dos surrealistas podem nos aparecer ainda mais fortes nos próprios textos do poeta, escritos em Rodez em 1946. Em um texto específico, Artaud aborda o tema da matéria pictural nos quadros surrealistas. Comparando-o ao seu corpus plástico-poético, duas idéias 
fundamentais serão postas em tensão: a cavidade (le creux) - a ser entendida em Artaud como a recorrente força do vazio, "impoder", esse estado de privação da linguagem, como figura que surge de seu gesto cruel e perfurador, tal qual vimos tratando; e a colocação em relevo (mise en relief), a ser entendida enquanto ereção de valores, objetos nomeados e representados pela pintura surrealista.

Artaud escreve: "Os quadros surrealistas são ultraclaros [...]. Deve-se notar que os pintores surrealistas não amam em geral a pintura vaga, e que sempre se encontram em suas telas objetos admiravelmente postos em relevo e desenhados." ${ }^{\text {* }}$ De acordo com o destino habitual oferecido ao campo do visível - esse que é fundado pelo contraste entre o racionalmente claro e o obscuro - Artaud privilegia a função de relevo. Seria ela, então, que tornaria visíveis os objetos "admiravelmente" ou "perfeitamente desenhados" nas telas surrealistas. Seu texto segue indicando a negra claridade dessas telas:

Desse modo então os quadros surrealistas são claros. Se não tivermos medo de sua sinistra luminosidade. E pode até ser que haja nos quadros surrealistas coisas brancas, mas em geral os quadros surrealistas são negros. [...]. Tudo que não possua um lado inquietante, insólito ou tenebroso não será jamais autenticamente surrealista.

O poeta nos remete aqui ao estado de insurreição de uma natureza recalcada que fornece aos quadros surrealistas sua inquietante clareza/transparência (clarté). É assim que Artaud sugere um princípio fundamental dos surrealistas, que consistiria na luta para pintar - revelando e relevando - uma outra natureza, recalcada na sociedade e nela apresentada como sombra. Tal sombra deveria substituir - tomar o lugar - (d)a cena real, (d)o vivente ou (d)o animado. O princípio surrealista, segundo Artaud, tomaria, desse modo, o partido da sombra como contrapeso do animado. Negro recalcado da luz do dia, natureza esquecida pela sociedade.

Em carta escrita em abril de 1947 a Hans Hartung, Artaud declara: "então Senhor Archtung eu desenho./ Quero dizer que não desenho mas sim que ao lado do que escrevo faço figuras que não são palavras, mas barras, não sombras". * Atendo-nos, momentaneamente, menos às "figuras" que constelam os cadernos de escola de Artaud, e mais à sua insistência em se diferenciar da arte do desenho, de seus efeitos de sombra e claridade, perceberíamos quão distante estaria sua plástica-poética das novas técnicas de pintura e colagem surrealistas. Por certo, o estatuto de sombra que Artaud nega às suas figuras também estaria indicando que elas não se
"Les tableaux surréalistes sont ultra-clairs [...]. On remarquera que les peintres surréalistes n'aiment pas en général la peinture vague et $q u$ on trouve toujours dans toutes leurs toiles des objets admirablement mis en relief et dessinés." (ARTAUD, Antonin. OEuvres complètes, t. XXI. Paris: Gallimard, 1985: 263.)

"Ainsi donc les tableaux surréalistes sont clairs. Quand on n'a pas peur de leurs lumières sinistres. Et je veux bien qu'il y ait dans les tableaux surréalistes des choses blanches, mais en général les tableaux surréalistes sont noirs [...]. Tout ce qui n'a pas un côté inquiétant, insolite ou ténébreux ne fut jamais authentiquement surréaliste, en effet. (Ibidem: 264.)

"Et puis Mr Archtung, je dessine./ Je veux dire que je ne dessine pas mais qu'à côté de ce que j'écris, je fais des figures qui ne sont pas des mots, mais des barres non des ombres." (ARTAUD, Antonin. OEuvres sur papier. Op. cit.: 46.) 
comportam como sombra de sua escrita. Elas não são palavras mas tampouco se comportam como fundo - ilustração - do texto. A sombra é outro ser e não seu contrapeso. A sombra é ela também um "corpo animado" que surge da cavidade ou, como temos visto, dessa relação ativa entre os corpos e os vazios.

Há aqui uma visibilidade aliada aos traços enquanto vetores de forças. $\mathrm{O}$ corpo que desenha não se restringe às mãos. A transformação da anatomia corporal, que se impõe no desenhar, igualmente se impõe ao olhar humano sobre seus desenhos. Lembremos que Artaud nos falou de uma transformação do olhar através de um "descolamento da retina", sublinhando, desse modo, um transtornar da lógica do visível e do invisível. Ora, é possível assinalar que a lógica das telas surrealistas, tal qual Artaud a percebe, seria uma lógica que cambia o visível (o que se vê) mas não a visibilidade (condição do ver). Seria preciso compreender com Artaud que a visibilidade não é somente uma qualidade do visível, mas, anteriormente, condição ou campo de possibilidade dos corpos. No tocante à prática dos desenhos, tal comportamento nos indica que o corpo, o olho, a retina não se pautam pelos paradigmas fisiológicos, e alteram a própria lógica do organismo orgânico ou da "chapa natureza", como disse o poeta. Tampouco Artaud iria inserir sua "retina descolada" no quadro das filosofias do espírito - olho signo de vidência, vínculo entre o mundo visível e o invisível, o natural e o sobrenatural, concreto e abstrato, corpo e espírito. Ao contrário, o "descolamento da retina" é indício de ruptura com um corpo que é presa do dualismo. Através dos seus desenhos-escritos ele nos introduz numa ruptura com a própria organização dos corpos, na qual não se trata mais de substituir uma lógica por outra (a do consciente cedendo à do inconsciente surrealista) mas de perfurar a lógica que nos envolve devolvendo-lhe sua própria arbitrariedade. Doravante, sua ruptura para com a espacialidade dos corpos viria necessariamente romper com a lógica temporal linear. As telas surrealistas nos apresentariam também outra ordem temporal que não a da linearidade. Tal ordem, do inconsciente - tomado enquanto automatismo pelo surrealismo -, não viria a se "descolar" da organização orgânica pautada pelas representaçōes nos "objetos postos em relevo e bem desenhados". Mesmo se a estranheza é inquietante, estamos ainda na ordem dos objetos nomeáveis. ${ }^{10}$

\footnotetext{
${ }^{10}$ Antonin Artaud no seu texto Les Tableaux surréalistes cita diversos pintores surrealistas, entre eles: Masson, Dalí, Giacometti, Picasso. Observamos a impossi-
} 
No projeto plástico de Artaud vemos, ao contrário, uma luta que opera com as malversações do corpo no domínio do visível. É um combate contra o corpo divido pelo espírito e esvaziado pelo organismo - combate contra o corpo/objeto, contra a possibilidade, portanto, de representá-lo. Assim, ele nos deixou sua luta: "É que essa luta em sua essência não cessa de ser significada concretamente pelas linhas e pelos pontos. Os pontos são semeados pela página. As linhas são essas que se poderia chamar de linhas intersticiais."

A idéia de uma linha intersticial poderia nos conduzir na reflexão acerca da ruptura espaço-temporal operada em seus desenhos-escritos, assim como na problematização da própria idéia de linha, aqui entendida como índice primordial do limite da escrita para o poeta. Ou seja: na precisão de que linha é recusada por sua plástica e do que ele entende por linha intersticial. Frisamos que o tempo rompido é esse da linearidade da vida tanto quanto esse da organização orgânica do corpo. Como efeito dessa ruptura, encontramos a significância não mais nos objetos nomeados, mas nos traços de um corpo semeado nos interstícios da linha. Tais linhas aparecem ainda assim: "Intersticiais elas são estando em suspenso no interior do movimento que as acompanha, movimento este que pressiona o sopro".*

Suspensão e sopro: elementos fundamentais da plástica poética de Artaud. O sopro é o movimento da linha ou dos pontos semeados. Poderíamos dizer que em torno à idéia de sopro são muitas as metáforas temporais possíveis e que não deixaram de inspirar os escritores ao longo dos tempos. Por exemplo, o sopro enquanto instante do esvaecer do tempo ou o sopro ausência, suspiro do passado. Seria preciso sublinhar que em Artaud o sopro ganha - para além do tempo - uma amplitude espacial justamente na presença das linhas intersticiais. Como se através de seus Cadernos desenhados e escritos acedêssemos a certa espacialização do tempo. Trata-se de romper com a linha da escrita e da leitura. O tempo ganha direções inusitadas que não somente essa da esquerda para a direita, ${ }^{11}$

bilidade de situar - no que diz respeito à questão do "relevo" - esses diferentes pintores sobre o mesmo plano. No entanto, parece-nos que a reflexão de Artaud continuaria permitindo elucidar alguns pontos da pintura de Salvador Dalí e se esboçaria deveras discutível para os outros pintores por ele citados.

${ }^{11}$ Lembro que a leitura de seus Cadernos escritos em Rodez e em Paris (Ivry sur Seine) nos obriga a um malabarismo do olhar, impedindo que ali encontremos somente um texto a ser lido da esquerda para direita. O desenho interfere de modo que a leitura ganha novas direções.
"C'est que cette lutte dans son essence ne cesse pas d'être signifiée concrètement par des lignes et par des points./ Ces points sont semés sur la page./ Ces lignes sont ce qu'on pourrait appeler des lignes interstitielles." (ARTAUD, Antonin. CEuvres complètes, t. XXI. Paris: Gallimard, 1985: 267.)

" "Interstitielles elles sont, étant comme en suspens dans le/ mouvement qu'elles accompagnent,/mouvement qui bouscule le souffle." (Ibidem: 267.) 
- "Je crois qu'il reste alors non dans l'espace mais dans le temps, à ce point de l'espace du temps où un souffle de derrière le coeur tient l'existence et la suspend." (Ibidem: 182.)

(ARTAUD, Antonin. CEuvres sur papier, Op. cit.: 110.) ou do nascimento para a morte. Esse movimento de suspensão é o que ele teria buscado desde os seus primeiros textos, que acaba por fazer com que o próprio limite da escrita seja a fonte e o motor de toda sua obra. Colocar em suspensão é ativar ainda mais esses próprios limites que estamos aqui analisando sob o ponto de vista dessa plástica-poética.

A partir de seus desenhos-escritos o tempo espacializado recorre ao sopro e às linhas intersticiais nos gestos ou movimentos que semeiam a página. As linhas intersticiais fissuram o tempo e escavam o espaço. Elas nos aparecem, desse modo, como espaço do tempo que conduz a musicalidade ${ }^{12}$ plástica de Artaud: "creio que ele fica agora não no espaço mas no tempo, nesse ponto do espaço do tempo onde um sopro que chega por trás do coração toma a existência e a suspende". *A suspensão é aliada do sopro. São os interstícios que se abrem. Neles deveriam surgir as forças geradoras de sua plástica-poética: "eu quero dizer da emoção geradora do desenho".*

Desse modo, podemos entender toda a sua plástica-poética como revolta e confronto com os limites da escrita. Em sua trajetória tais limites foram responsáveis pela sua própria inclusão no seio da literatura. Quando o editor da Nouvelle Revue Française, Jacques Rivière, recusa, em 1924, a publicação de seus poemas, lê em seguida uma carta do escritor questionando sua recusa que o faz imediatamente querer publicá-la. Artaud inscreve, mesmo sem saber, sua relação com a escrita sob o signo de uma perda, de uma falha intrínseca ao pensamento e à própria escrita. Doravante ele experimentará escrever sob o paradoxo de uma ausência de escrita. O que buscamos desenvolver foi como esse paradoxo foi imensamente produtivo, gerando um caminho de experimentação que, não sem dor, acabou por expandir a própria noção de texto no interior das experiências artísticas do século XX.

Resta sublinhar que a tal "espontaneidade do traço" - afastada de um reduto automático - viria se conciliar com a tentativa insistente de crivar os corpos e devolver-lhes os vácuos, as passa-

\footnotetext{
${ }^{12}$ Em nosso trabalho - por motivos de recorte da questão - estamos tratando a musicalidade na sua íntima relação com a poética de Artaud. Mas não deixamos de indicar que Artaud em muito expandiu suas relações com o domínio da música. Suas performances teatrais já na década de trinta exploravam sons, ruídos, percussões que posteriormente seriam a base mesma da música concreta. Para tanto, ver, por exemplo: CHALOSSE, Marc. "Artaud remix". In: Revue Europe. Numéro Artaud, n.873-874, jan-fév. 2002.
} 
gens. Essa espontaneidade seria o próprio exercício face ao limite: subverter a ordem e a organização dos corpos começando pelo próprio corpo da língua - a letra, a linha, o texto. É assim que vemos as explosões desses desenhos-escritos dando ênfase às letras desenhadas e aos textos feitos de palavras "ilegíveis" (as glossolalias de Artaud), mas prenhes de sonoridades físicas. Essas são, entre muitas outras, as maneiras que o poeta experimentou como saídas possíveis para sua exasperante experiência com uma linguagem parti$d a .^{13}$ No vácuo dessa linguagem que partiu (nessa sutil passagem ou nas linhas intersticiais), o traço vai agir: ele porta a força geradora em suas nuanças de quebra, de corte, de falha. O traço respira enquanto a linha silencia. Dele ouvimos o balançar do corpo, a mão que treme, o sopro que infla.

${ }^{13}$ Em 1947 Artaud escreve poema que assim se inicia: "Dez anos que a linguagem partiu e no seu lugar entrou esse trovão atmosférico (...)”. 


\section{Ana Kiffer}

Ana Kiffer é Doutora em Literatura Comparada (UERJ, 2002), Professora Assistente da PUC-RJ, Departamento de Letras. É atual Coordenadora da Pós-Graduação em Letras da PUC-Rio. Em 2007 foi eleita Directeur de Programme no Colégio Internacional de Filosofia em Paris. Suas pesquisas atuais versam sobre: "Escrita e fome - engajamento literário ao longo do século XX" e "Escrita e corpo - a intensidade o excesso e o 'fora de si'”. É especialista na obra do escritor francês Antonin Artaud tendo publicado, entre outros artigos "Les Corps de La Faim" na Revue Europe, e o livro Antonin Artaud-uma poética do pensamento, Espanha, Coruña, 2003.

Palavras-chave: "impoder"; falha; limite; traço; desenho-escrito.
Key words: "powerlessness"; failure; limit; writing; absence; poetics-plastic.

Mots-clés: "l'impouvoir"; faille; limite; trait; dessinécrit.

\section{Resumo}

Esse trabalho pretende abordar a experiência do escritor Antonin Artaud (1896-1948) face ao que considerou serem os limites da escrita: seu impoder, suas palavras falhadas. Mostraremos como o escritor explora esses limites (vividos enquanto perda, ausência, impotência), de modo a fazer da própria escrita uma experiência de explosão dos seus quadros e enquadramentos, através do que nomeou desenhos-escritos.

\section{Abstract}

This article aims to review the works of Antonin Artaud (18961948) taking into account the relation between the limits of writing (felt by the poet through words like absence of spirit and "powerlessness" of language) and his last works named by him "dessins-écrits" (writingsdrawings).

\section{Résumé}

Ce texte analyse l'expérience de l'écrivain français Antonin Artaud (1896-1948) en soulignant ce qu'il a nommé comme l'impouvoir de la pensée ainsi que ses mots ratés. Nous voulons montrer que c'est à partir d'une exploitation de ces limites de l'écriture, vécues en tant qu'absence, perte et impuissance, que le poète arrivera à bouleverser la notion du texte au profit d'une écriture dessinée. 